\title{
Correlation between gene polymorphisms of CYP1A1, GSTP1, ERCC2, XRCC1, and $X R C C 3$ and susceptibility to lung cancer
}

\author{
H.X. $\mathrm{Liu}^{1}$, J. $\mathrm{Li}^{2}$ and B.G. Ye \\ ${ }^{1}$ Department of Medical \& Information Engineering, \\ Guangdong Pharmaceutical University, Guangzhou, China \\ ${ }^{2}$ Huacao Community Health Service Center, Shanghai, China \\ ${ }^{3}$ Guangdong Vocational College of Food and Drugs, Guangzhou, China \\ Corresponding author: H.X. Liu \\ E-mail: hongxiuliuzxc@sina.com
}

Genet. Mol. Res. 15 (4): gmr15048813

Received May 16, 2016

Accepted August 28, 2016

Published November 3, 2016

DOI http://dx.doi.org/10.4238/gmr15048813

Copyright (C) 2016 The Authors. This is an open-access article distributed under the terms of the Creative Commons Attribution ShareAlike (CC BY-SA) 4.0 License.

\begin{abstract}
Lung cancer is a common malignant tumor that is characterized by high morbidity and poor prognosis. Studies suggest that an individual's genetic background affects the risk of developing lung cancer. Therefore, we investigated the relationship between gene polymorphisms and susceptibility to lung cancer. We recruited 308 primary lung cancer patients as subjects and 253 healthy adults as controls. After extraction of DNA from blood samples, gene polymorphisms in CYP1A1, GSTP1, $E R C C 2, X R C C 1$, and $X R C C 3$ were investigated by polymerase chain reaction and restriction fragment length polymorphism. The frequencies of the genotypes in both groups were investigated to obtain odds ratios and $95 \%$ confidence intervals, and correlation analysis was carried out. The analysis results showed that the following polymorphisms were correlated with susceptibility to lung cancer: rs4646903 in CYP1A1 (P <
\end{abstract}


0.001), rs1048943 in CYP1A1 ( $\mathrm{P}<0.001)$, rs1695 in GSTP1 $(\mathrm{P}<0.05)$, rs13181 in ERCC2 $(\mathrm{P}<0.001)$, and rs25487 in XRCC1 $(\mathrm{P}<0.05)$; no such correlation existed in rs861539 in $X R C C 3(\mathrm{P}>0.05)$. The study revealed that the more high-risk gene polymorphisms a patient carries, the greater the risk of developing lung cancer. Carriers of rs4646903 in CYP1A1, rs 1048943 in CYP1A1, rs1695 in GSTP1, rs13181 in ERCC2, and rs25487 in XRCCl are more likely to develop lung cancer.

Key words: Lung cancer; CYP1A1, GSTP1, ERCC2, XRCC1, XRCC3; Gene polymorphism; Correlation analysis

\section{INTRODUCTION}

Lung cancer is a common malignant tumor that is characterized by high morbidity and poor prognosis (Malvezzi et al., 2013). Early diagnosis and treatment can effectively improve the prospects for patients with lung cancer. However, the pathogenesis of lung cancer is still not clear. Existing studies have shown that long-term smoking can increase the risk of lung cancer, and that one of every 10 smokers will develop cancer (Hecht et al., 2016). Moreover, risk studies on different populations of lung cancer patients suggest that risks are different among smokers. This indicates that smokers from different genetic backgrounds have different levels of sensitivity to lung cancer (Malvezzi et al., 2015). However, gene mutation is the main cause of adenocarcinoma, which is another subtype of lung cancer. To date, lung cancer therapy has been based on operations and multidisciplinary and comprehensive treatment.

Smoking or long-term exposure to other carcinogens can damage genomic DNA, which can ultimately lead to cancer (Hecht et al., 1999). Several genes are associated with the occurrence of lung cancer (Liu, et al., 2015); epidermal growth factor receptor $(E G F R)$, anaplastic lymphoma kinase $(A L K)$, and V-Ki-ras2 Kirsten rat sarcoma viral oncogene homolog $(K R A S)$ are the most commonly mutated genes in lung cancer patients (Choi et al., 2016). However, the drugs that are commonly used to treat such patients are not universally effective. The expression of genes that are associated with the metabolism of carcinogens, such as the cytochrome oxidase (cytochrome P450, CYP) superfamily and the glutathione S-transferase (glutathione-S-transferases, GST) superfamily, may be closely related to individual susceptibility to cancer (García-González et al., 2012; Ghoshal et al., 2014). Moreover, DNA damage repair-related gene expression levels have a major impact on the incidence of malignant tumors (Brosh, 2013). Mota et al. (2015) found that genetic polymorphisms can influence the expression of genes and the activity of the proteins they encode, which may ultimately affect an individual's risk of developing cancer (Chen et al., 2012).

Therefore, in this study we investigated the relationship between the occurrence of polymorphisms in CYP1A1, GSTP1, nucleotide excision repair cross-complementation group gene 2 (ERCC2), X-ray repair cross-complementing gene (XRCC1), and X-ray repair crosscomplementing gene 3 (XRCC3), and susceptibility to lung cancer.

\section{MATERIAL AND METHODS}

\section{Subjects}

Three hundred and eight patients with lung cancer, aged $51 \pm 6.2$ years, were randomly

Genetics and Molecular Research 15 (4): gmr15048813 
recruited between June 2008 and June 2014 from Guangdong Pharmaceutical University. All patients were diagnosed with primary lung cancer by histopathological analysis and computed tomography scans of the chest. The subjects were divided into one of four categories according to the international classification of oncology and pathology analysis: adenocarcinoma, squamous cell lung carcinoma, small cell lung cancer, or large cell lung cancer. Two hundred and fifty-three healthy volunteers, aged $50 \pm 5.7$ years, were selected as controls during the same period; the control volunteers were all free from clinical cancer, ischemic heart disease, or chronic respiratory diseases. The present study received the approval and supervision of the Ethics Committee, and informed consent from the patients or their legal guardians.

\section{Gene polymorphisms}

Polymorphisms and the distribution of genes CYP1A1, ERCC2, XRCC1, and XRCC3 were detected by polymerase chain reaction and restriction fragment length polymorphism (PCR-RFLP). All subjects had fasted since the morning, and blood was collected in 5-mL ethylenediaminetetraacetic acid (EDTA) anticoagulant-coated tubes (BD Biosciences, San Jose, CA, USA); DNA was isolated from the blood samples using a blood DNA kit (Qiagen). DNA content was measured using a UV spectrophotometer (Merinton) and the samples were stored at $-20^{\circ} \mathrm{C}$. The rs 4646903 and rs 1048943 polymorphisms of CYP1A1, rs 1695 of GSTP1, rs13181 of ERCC2, rs25487 of XRCC1, and rs861539 of XRCC3 were selected for analysis. Primers were designed for PCR-RFLP detection according to the National Center for Biotechnology Information (NCBI) database and the human genome sequence data for CYP1A1, GSTP1, ERCC2, XRCC1, and XRCC3 genes; they were synthetized by Sangon and are shown in Table 1. We used the isolated DNA as a template for PCR amplification. The PCR system comprised $0.5 \mu \mathrm{L}$ primers $(50 \mathrm{pM}), 0.2 \mu \mathrm{L}$ Taq, $2.5 \mu \mathrm{L}$ 10X PCR buffer, $1.0 \mu \mathrm{L}$ dNTP $(5 \mathrm{mM})$, and double-distilled $\mathrm{H}_{2} \mathrm{O}$ making a total volume of $25.0 \mu \mathrm{L}$. The PCR regimen was: $95^{\circ} \mathrm{C}$ for $5 \mathrm{~min}$; followed by 30 cycles of $95^{\circ} \mathrm{C}$ for $30 \mathrm{~s}, 60^{\circ} \mathrm{C}$ for $30 \mathrm{~s}$, and $72^{\circ} \mathrm{C}$ for $1 \mathrm{~min}$; and a final stage at $72^{\circ} \mathrm{C}$ for $10 \mathrm{~min}$. The $C Y P 1 A 1, E R C C 2, X R C C 1$, and $X R C C 3$ amplification products were incubated with restriction enzymes (NEB) and digested at $37^{\circ} \mathrm{C}$ for $16 \mathrm{~h}$. The digestion products were then analyzed by electrophoresis at $120 \mathrm{~V}$ for $20 \mathrm{~min}$ (the different polymorphic locus restriction enzymes used are shown in Table 1). GSTP1 was amplified by outer primers GSTP1-exF and GSTP1-exR and inner primers GSTP1-inF and GSTP1-inR.

\begin{tabular}{|c|c|c|}
\hline Name & Sequence & Restriction enzyme \\
\hline CYP1A1-M1F & 5'-TTCCACCCGTTGCAGGATAGCC-3' & \multirow[t]{2}{*}{$M s p \mathrm{I}$} \\
\hline CYP1A1-M1R & 5'-CTGTCTCCCTCTGGTTACAGGAAG-3' & \\
\hline CYP1A1-M2F & 5'-CTGTCTCCCTCTGGTTACAGGAAGC-3' & \multirow[t]{2}{*}{ BsrDI } \\
\hline CYP1A1-M2R & 5'-TTCCACCCGTTGCAGCAGGATAGCC-3' & \\
\hline GSTP1-exF & 5'-CAGGTGTCAGGTGAGCTCTGAGCACC-3' & \multirow[t]{2}{*}{-} \\
\hline GSTP1-exR & 5'-ATAAGGGTGCAGGTTGTGTCTTGTCCC-3' & \\
\hline GSTP1-inF & 5'-CGTGGAGGACCTCCGCTGCAAATCCA-3' & \multirow[t]{2}{*}{-} \\
\hline GSTP1-inR & 5'-CACATAGTTGGTGTAGATGAGGGATAC-3' & \\
\hline ERCC2-M1F & 5'-CCCCCTCTCCCTTTCCTCTG-3' & \multirow[t]{2}{*}{ MboII } \\
\hline ERCC2-M1R & 5'-AACCAGGGCCAGGCAAGAC-3' & \\
\hline XRCC1-M1F & 5'-CAAGTACAGCCAGGTCCTAG-3' & \multirow[t]{2}{*}{$M s p \mathrm{I}$} \\
\hline XRCC1-M1R & 5'-CCTTCCCTCATCTGGAGTA-3' & \\
\hline XRCC3'-M1F & 5'-GCCTGGTGGTCATCGACTC-3' & NlaIII \\
\hline XRCC3'-M1R & 5'-GCACTGCTCAGCTCACGCACC-3' & \\
\hline
\end{tabular}

Genetics and Molecular Research 15 (4): gmr15048813 


\section{Statistical analysis}

Statistical analysis of variance or the $t$-test between groups was carried out using the SPSS 20.0 software. The representative sample group was investigated for Hardy-Weinberg equilibrium. The correlation analysis between the polymorphisms of CYP1A1, GSTP1, ERCC2, $X R C C 1$, and $X R C C 3$ and the susceptibility to lung cancer was performed by multiple-logistic regression (univariate logistic regression). The results are reported as odds ratios (ORs) and $95 \%$ confidence intervals (95\%CIs); $\mathrm{P}$ was defined as bilateral probability and a $\mathrm{P}<0.05$ was considered a significant difference.

\section{RESULTS}

\section{General information about the subjects}

All statistical analysis results for the clinical data are shown in Table 2. In the present study, there were 308 cases of lung cancer in the patient group (161 cases of lung adenocarcinoma, 87 cases of lung squamous cell carcinoma, 46 cases of small cell lung cancer, and 14 cases of large cell lung cancer). The patient group comprised 192 males and 116 females with a mean age of $51 \pm 6.2$ years; 206 cases had a history of smoking and 189 cases had a history of alcohol consumption. The control group comprised 253 healthy adults recruited over the same period as the patients; there were 145 males and 108 females with a mean age of $50 \pm 5.7$ years; 113 cases had a history of smoking and 117 cases had a history of alcohol consumption. The healthy controls had an average of $10.2 \pm 3.1$ years of education. There was no statistically significant difference between the groups in terms of age, gender, years of education, gender composition, or any other aspect $(\mathrm{P}>0.05)$.

Table 2. Clinical data of patient and control groups.
\begin{tabular}{l|c|c|c}
\hline & Controls (N =253) & Patients (N=308) & P value \\
\hline Average age & $50 \pm 5.7$ & $51 \pm 6.2$ & $>0.05$ \\
\hline Gender (male/female) & $145 / 108$ & $192 / 116$ & $>0.05$ \\
\hline Lung adenocarcinoma & 0 & 161 & $<0.001$ \\
\hline Lung squamous cell carcinoma & 0 & 87 & $<0.001$ \\
\hline Small cell lung cancer & 0 & 46 & $<0.001$ \\
\hline Large cell lung cancer & 0 & $206 / 102$ & $<0.001$ \\
\hline History of smoking (yes/no) & $113 / 140$ & $189 / 119$ & $<0.001$ \\
\hline History of drinking (yes/no) & $117 / 136$ & $10.5 \pm 3.3$ & $<0.001$ \\
\hline Years of education & $10.2 \pm 3.1$ & & $>0.05$ \\
\hline
\end{tabular}

\section{PCR-RFLP investigation of gene polymorphism results}

The rs4646903 polymorphism of CYP1A1 is located in the $3^{\prime}$ thymine (T) non-coding region of the mutated cytosine (C), forming an $M s p$ I restriction site that yielded a 340-bp fragment length PCR product. Figure 1A shows the electrophoresis result for the product after $M s p$ I digestion. The homozygous mutation produced two fragments (200 and $140 \mathrm{bp}$ ), and the heterozygous mutation produced three fragments $(340,200$, and $140 \mathrm{bp})$, whereas wild-type CYP1A1 could not be digested. 

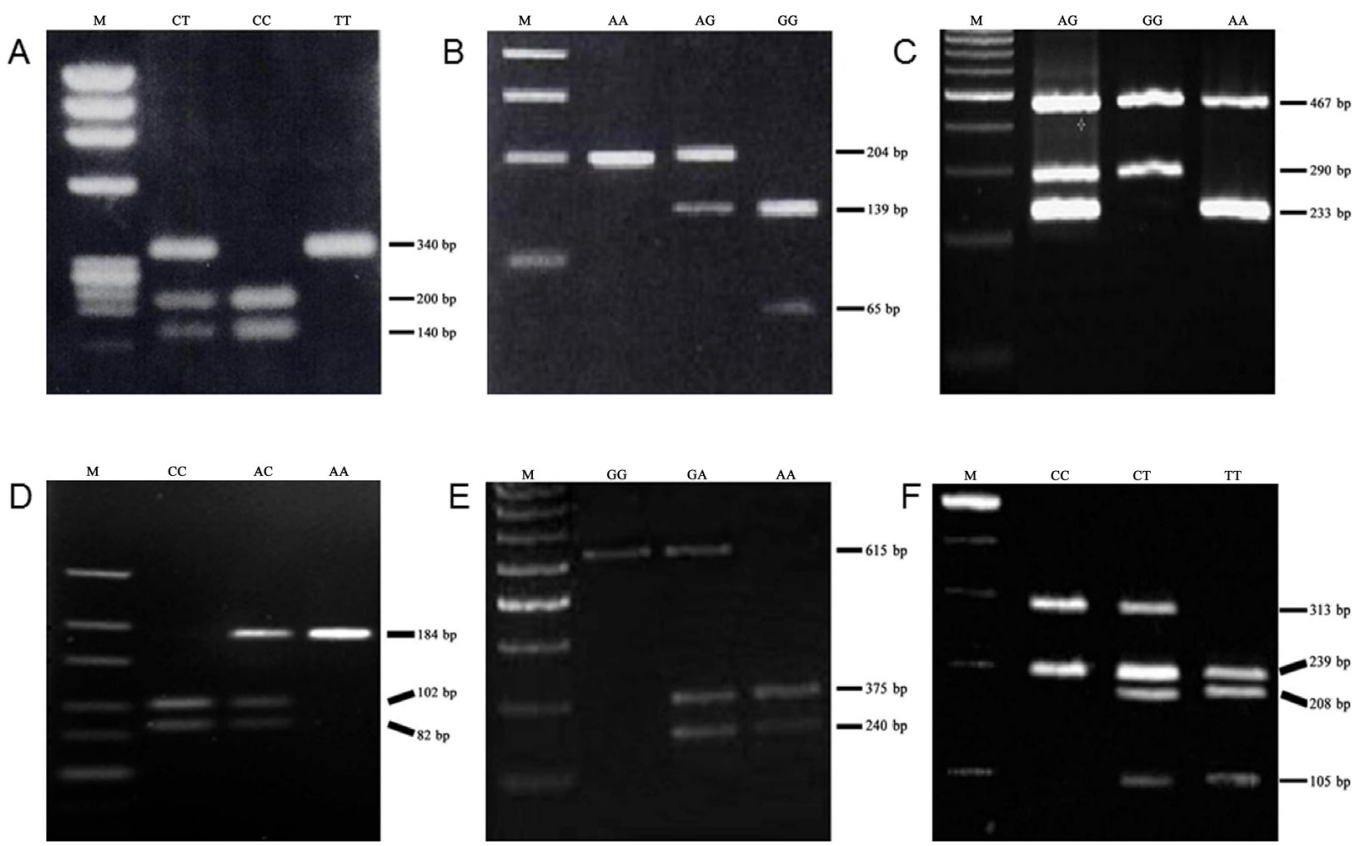

Figure 1. Gene polymorphisms of $C Y P 1 A 1$, GSTP1, ERCC2, XRCC1, and XRCC3 related to lung cancer. A. CYP1A1 rs4646903 gene polymorphism enzyme map. CT: heterozygous rs4646903 locus genotype; CC: homozygous rs4646903 locus genotype; TT: homozygous rs4646903 locus genotype. B. CYP1A1 rs1048943 gene polymorphism enzyme map. AA: wild-type rs 1048943 locus genotype; AG: heterozygous rs 1048943 locus genotype; GG: homozygous rs1048943 locus genotype. C. GSTP1 rs1695 gene polymorphism PCR product map. AA: wild-type rs1695 locus genotype; AG: heterozygous rs 1695 locus genotype; GG: homozygous rs1695 locus genotype. D. ERCC2 rs13181 gene polymorphism restriction map. CC: homozygous rs13181 locus genotype; AC: heterozygous rs13181 locus genotype; AA: homozygous rs13181 locus genotype. E. XRCC1 rs25487 gene polymorphism restriction map. GG: homozygous wild-type rs25487 locus genotype; AG: heterozygous rs 25487 locus genotype; AA: homozygous rs25487 locus genotype. F. XRCC3 rs861539 gene polymorphism restriction map. CC: homozygous wild-type rs861539 locus genotype; CT: heterozygous rs861539 locus genotype; TT: homozygous rs861539 locus genotype. Lane M: molecular marker.

The rs1048943 polymorphism of CYP1A1 is located outside exon 7 in a sequence of adenine (A) mutated to guanine (G), forming a BsrDI restriction site that yielded a 204-bp fragment length PCR product. The electrophoresis result for the product after BsrDI digestion is shown in Figure 1B. The homozygous mutation produced two fragments (139 and $65 \mathrm{bp}$ ), and the heterozygous mutation produced three fragments (204, 139, and $65 \mathrm{bp})$, whereas wildtype CYP1A1 could not be digested.

The rs1695 polymorphism of GSTP1 is located outside exon 5 in a sequence of adenine (A) mutated to guanine $(\mathrm{G})$ in the inner and outer primer. As shown in Figure 1C, the amplification products of the different genotypes are different. The homozygous mutation produced two fragments (139 and $65 \mathrm{bp}$ ), and the heterozygous mutation produced three fragments $(204,139$, and $65 \mathrm{bp})$, whereas wild-type GSTP1 could not be digested.

The rs13181 polymorphism of ERCC2 produced a coding sequence of adenine (A) mutated to cytosine (C). The electrophoresis result of the product after BsrDI digestion is 
shown in Figure 1D. The homozygous mutation produced two fragments (467 and $290 \mathrm{bp}$ ), and the heterozygous mutation produced three fragments (184, 102, and $82 \mathrm{bp}$ ), whereas wildtype $E R C C 2$ produced a single $184-\mathrm{bp}$ fragment.

The polymorphisms of XRCC1 and XRCC3 were defined as follows. The rs25487 polymorphism of XRCC1 is located on exon 10 outside guanine (G) mutated to adenine (A). The products of the XRCCl gene after MspI digestion are shown in Figure 1E. The rs861539 polymorphism of $X R C C 3$ is cytosine $(C)$ mutated to thymine $(T)$, which is located in exon 7. The products of the XRCC3 gene after NlaIII digestion are shown in Figure 1F.

\section{Respiratory chain gene polymorphism and lung cancer susceptibility analysis}

Hardy-Weinberg equilibrium was tested by the goodness of fit test in the healthy control group; the results showed that three respiratory chain gene polymorphisms (CYP1A1 rs4646903, CYP1A1 rs1048943, and GSTP1 rs1695) had loci that met the Hardy-Weinberg equilibrium (P $>0.05$ ), indicating that the present study sample was representative. The correlation analysis between the polymorphisms of CYP1A1, CYP1A1, and GSTP1 and susceptibility to lung cancer is shown in Table 3. In the control group, the homozygous mutation (CC type) of rs 4646903 accounted for $11.4 \%$ in the CYP1A1 gene, the homozygous mutation (GG type) of rs 1048943 accounted for $5.5 \%$ in the CYP1A1 gene, and the homozygous mutation (GG type) of rs 1695 accounted for $1.6 \%$ in the GSTP 1 gene. The relevance of each gene polymorphism to the risk of lung cancer was defined by odds ratios (OR) and $95 \%$ confidence intervals $(95 \% \mathrm{CI})$ as follows: $\mathrm{rs} 4646903$ of $\mathrm{CYP} 1 \mathrm{Al}(\mathrm{OR}=2.62,95 \% \mathrm{CI}=1.61-4.28, \mathrm{P}<0.001)$; rs 1048943 of CYP1A1 (OR $=2.85,95 \% \mathrm{CI}=1.54-5.32, \mathrm{P}<0.001)$; and $\mathrm{rs} 1695$ of GSTP1 (OR $=3.21,95 \% \mathrm{CI}=1.12-9.30, \mathrm{P}<0.05)$. These results show that there is a correlation between the polymorphic loci and susceptibility to lung cancer.

Table 3. Correlation between respiratory chain gene polymorphisms and susceptibility to lung cancer.

\begin{tabular}{l|c|c|c|c|c}
\hline Gene & Polymorphism & Controls [N (\%)] & Patients [N (\%)] & OR (95\%CI) & P value \\
\hline CYP1A1 rs4646903 & TT & $113(44.7 \%)$ & $99(32.1 \%)$ & $1.0($ Reference) & \\
\hline & TC & $111(43.9 \%)$ & $145(47.1 \%)$ & $1.51(1.06-2.11)$ & $<0.05$ \\
\hline & CC & $29(11.4 \%)$ & $64(20.8 \%)$ & $2.62(1.61-4.28)$ & $<0.001$ \\
\hline & TC+CC & $140(55.3 \%)$ & $209(67.9 \%)$ & $1.72(1.25-2.38)$ & $<0.001$ \\
\hline CYP1A1 rs1048943 & AA & $156(61.7 \%)$ & $165(53.6 \%)$ & $1.0($ Reference $)$ & \\
\hline & AG & $83(32.8 \%)$ & $107(34.7 \%)$ & $1.19(0.84-1.66)$ & $>0.05$ \\
\hline & GG & $14(5.5 \%)$ & $36(11.7 \%)$ & $2.85(1.54-5.32)$ & $<0.001$ \\
\hline & AG+GG & $97(38.3 \%)$ & $143(46.4 \%)$ & $1.41(1.02-1.92)$ & $<0.05$ \\
\hline & AA & $193(76.3 \%)$ & $215(69.8 \%)$ & $1.0($ Reference $)$ & \\
\hline & AG & $56(22.1 \%)$ & $80(26.0 \%)$ & $1.38(0.94-1.97)$ & $>0.05$ \\
\hline & GG & $4(1.6 \%)$ & $13(4.2 \%)$ & $3.21(1.12-9.30)$ & $<0.05$ \\
\hline & AG+GG & $60(23.7 \%)$ & $93(30.2 \%)$ & $1.48(1.04-2.11)$ & $<0.05$ \\
\hline
\end{tabular}

\section{Correlation analysis of DNA repair gene polymorphisms and susceptibility to lung cancer}

Correlation analysis was conducted on the polymorphisms of three genes that are involved in DNA repair (ERCC2,XRCC1, and XRCC3) and susceptibility to lung cancer (Table 4). In the control group, the homozygous mutation ratio of the loci of rs13181 of $E R C C 2$, rs 25487 of $X R C C 1$, and rs 861539 of $X R C C 3$ were $1.6,4.0$, and $2.0 \%$, respectively. The relevance of each gene polymorphism to the risk of lung cancer was defined by OR and $95 \% \mathrm{CI}$ as follows: $\mathrm{rs} 13181$ of $E R C C 2(\mathrm{OR}=5.61,95 \% \mathrm{CI}=1.99-15.8, \mathrm{P}<0.001)$; and 
rs 25487 of $X R C C 1(\mathrm{OR}=2.61,95 \% \mathrm{CI}=1.35-4.96, \mathrm{P}<0.05)$. The results show that there is a correlation between these polymorphic loci and susceptibility to lung cancer. However, there was no significant correlation between the polymorphic loci of rs861539 of XRCC3 (OR $=$ $0.99,95 \% \mathrm{CI}=0.69-1.41, \mathrm{P}>0.05)$ and susceptibility to lung cancer.

Table 4. DNA repair-related gene polymorphism associated with susceptibility to lung cancer.

\begin{tabular}{l|c|c|c|c|c}
\hline Gene & Polymorphism & Controls [N (\%)] & Patients [N (\%)] & OR (95\%CI) & P value \\
\hline$E R C C 2$ rs13181 & AA & $206(81.4 \%)$ & $221(71.8 \%)$ & 1.0 (Reference) & \\
\hline & AC & $43(17.0 \%)$ & $74(24.0 \%)$ & $1.62(1.06-2.42)$ & $<0.05$ \\
\hline & CC & $4(1.6 \%)$ & $13(4.2 \%)$ & $5.61(1.99-15.8)$ & $<0.001$ \\
\hline & AC+CC & $47(18.63 \%)$ & $87(28.2 \%)$ & $1.89(1.28-2.78)$ & $<0.001$ \\
\hline$X R C C 1$ rs25487 & GG & $162(64.0 \%)$ & $162(52.6 \%)$ & $1.0($ Reference) & \\
\hline & AG & $81(32.0 \%)$ & $114(37.0 \%)$ & $1.39(0.98-1.95)$ & $>0.05$ \\
\hline & AA & $10(4.0 \%)$ & $32(10.4 \%)$ & $2.61(1.35-4.96)$ & $<0.05$ \\
\hline$X R C C 3$ rs861539 & AG+AA & $91(36.0 \%)$ & $146(47.4 \%)$ & $1.55(1.11-2.14)$ & $<0.05$ \\
\hline & CC & $197(77.9 \%)$ & $235(76.3 \%)$ & $1.0($ Reference) & \\
\hline & CT & $51(20.2 \%)$ & $65(21.1 \%)$ & $0.97(0.64-1.40)$ & $>0.05$ \\
\hline & TT & $4(2.0 \%)$ & $8(2.6 \%)$ & $1.33(0.48-3.77)$ & $>0.05$ \\
\hline & CT+TT & $55(22.2 \%)$ & $73(23.7 \%)$ & $0.99(0.69-1.41)$ & $>0.05$ \\
\hline
\end{tabular}

Analysis of combined multi-gene polymorphisms and susceptibility to lung cancer

Table 5 shows the results of the correlation analysis of combined multi-gene respiratory chain-related gene polymorphisms (rs4646903 of CYP1A1 and rs1695 of GSTP1) and susceptibility to lung cancer, and three DNA repair gene polymorphisms (rs13181 of $E R C C 2$, rs 25487 of $X R C C 1$, and rs 861539 of $X R C C 3$ ) and susceptibility to lung cancer. We found that susceptibility to lung cancer increased significantly with an increase in the number of gene polymorphisms. There was a greater than 4-fold increase in susceptibility to lung cancer when CYP1A1, GSTP1, and the three DNA repair gene polymorphisms were present at the same time. Moreover, we found that the correlation between rs13181 of ERCC2 and susceptibility to lung cancer was the highest $(\mathrm{OR}=5.74,95 \% \mathrm{CI}=1.7-15.6)$.

Table 5. Correlation between combined gene polymorphisms and susceptibility to lung cancer.

\begin{tabular}{|c|c|c|c|c|c|}
\hline CYP1A1 & GSTP1 & DNA repair gene & Treatment/control & OR $(95 \% \mathrm{CI})$ & P value \\
\hline rs 4646903 & rs1695 & $\mathrm{rs} 13181$ & & & \\
\hline 0 & 0 & 0 & $59 / 71$ & 1.0 (Reference) & \\
\hline 1 & 0 & 0 & $99 / 82$ & $1.48(0.98-2.27)$ & $>0.05$ \\
\hline 0 & 1 & 0 & $15 / 22$ & $0.92(0.44-1.80)$ & $>0.05$ \\
\hline 0 & 0 & 1 & $14 / 16$ & $1.11(0.52-2.41)$ & $>0.05$ \\
\hline 1 & 1 & 0 & $48 / 30$ & $2.08(1.21-3.56)$ & $<0.05$ \\
\hline 1 & 0 & 1 & $43 / 23$ & $2.48(1.36-4.40)$ & $<0.05$ \\
\hline 0 & 1 & 1 & $11 / 3$ & $5.87(1.67-20.4)$ & $<0.05$ \\
\hline 1 & 1 & 1 & $19 / 5$ & $5.74(1.70-15.6)$ & $<0.001$ \\
\hline rs 4646903 & rs1695 & rs 25487 & & & \\
\hline 0 & 0 & 0 & $38 / 57$ & 1.0 (Reference) & \\
\hline 1 & 0 & 0 & $73 / 68$ & $1.80(1.07-2.93)$ & $<0.05$ \\
\hline 0 & 1 & 0 & $18 / 15$ & $1.76(0.86-3.70)$ & $>0.05$ \\
\hline 0 & 0 & 1 & $35 / 30$ & $1.77(0.97-3.22)$ & $>0.05$ \\
\hline 1 & 1 & 0 & $33 / 21$ & $2.53(1.32-4.81)$ & $<0.05$ \\
\hline 1 & 0 & 1 & $69 / 37$ & $2.63(1.52-4.47)$ & $<0.001$ \\
\hline 0 & 1 & 1 & $7 / 11$ & $1.58(0.65-4.14)$ & $>0.05$ \\
\hline 1 & 1 & 1 & $34 / 13$ & $4.09(2.01-8.24)$ & $<0.001$ \\
\hline rs4646903 & rs1695 & rs861539 & & & \\
\hline 0 & 0 & 0 & $63 / 63$ & 1.0 (Reference) & $>0.05$ \\
\hline 1 & 0 & 0 & $115 / 83$ & $1.45(0.96-2.23)$ & $>0.05$ \\
\hline 0 & 1 & 0 & $21 / 21$ & $1.14(0.55-2.14)$ & $<0.05$ \\
\hline 0 & 0 & 1 & $10 / 25$ & $0.43(0.21-0.90)$ & $>0.05$ \\
\hline 1 & 1 & 0 & $36 / 30$ & $1.46(0.83-2.57)$ & $>0.05$ \\
\hline 1 & 0 & 1 & $27 / 23$ & $1.13(0.65-2.11)$ & $<0.001$ \\
\hline 0 & 1 & 1 & $5 / 4$ & $1.24(0.36-4.43)$ & $>0.05$ \\
\hline 1 & 1 & 1 & $31 / 5$ & $4.93(2.01-12.5)$ & $>0.05$ \\
\hline
\end{tabular}

Genetics and Molecular Research 15 (4): gmr15048813 


\section{DISCUSSION}

Studies have shown that abnormal expression levels of genes related to the metabolism of carcinogens in cells, such as those that encode the CYP superfamily of proteins, the GST superfamily of proteins, or the DNA repair-associated proteins, might lead to an increase in the risk of developing cancer (Li et al., 2014; Mota et al., 2015; Zhao et al., 2015). In the present study, we used PCR and PCR-RFLP to investigate gene polymorphisms in key respiratory chain genes that take part in DNA damage repair, including CYP1A1, GSTP1, ERCC2, XRCC1, and $X R C C 3$. We then conducted a correlation analysis of the relationship between polymorphisms in these genes and susceptibility to lung cancer. We discovered that rs4646903 and rs 1048943 of CYP1A1, rs1695 of GSTP1, rs13181 of ERCC2, and rs25487 of XRCC1 are correlated with susceptibility to lung cancer, but there was no significant correlation between rs 861539 of $X R C C 3$ and susceptibility to lung cancer. We also found that when an individual carries a large number of polymorphisms related to the risk of lung cancer, their risk of developing lung cancer increases significantly.

CYP1A1 is involved in the metabolization of a variety of carcinogens, including tobacco benzopyrene and other polycyclic aromatic hydrocarbons (Abdull Razis et al., 2015). Studies have shown that the $\mathrm{C}$ allele in the rs 4646903 polymorphism of CYP1A1 can increase the induction rate of CYP1A1, which may increase the risk of lung cancer in smokers (Abbas et al., 2014). The rs 1048943 polymorphism of CYP1A1 can cause Ile at amino acid number 462 to mutate to Val, which affects the activity of the CYP1A1 protein. Ultimately, it also affects the metabolization of tobacco carcinogens, increasing susceptibility to lung cancer (Xu et al., 2013).

The rs1695 polymorphism of GSTP1 can cause Ile at amino acid number 105 of GSTP1 to mutate to Val leading to reduced activity of the GSTP1 protein, which also affects susceptibility to lung cancer (Ibarrola-Villava et al., 2012). That particular polymorphism is most prevalent in African-Americans, followed by Caucasians and Asians (Hezova et al., 2012). Like CYP1A1, GSTP1 is involved in the metabolic processing of tobacco carcinogens such as 7,8-epoxy-9,10-dihydroxyvitamin acrolein and benzopyrene, which affects susceptibility to lung cancer (Li et al., 2010); this result was confirmed in the present study.

Currently, at least four DNA damage repair pathways are known including BER, NER, DSBR, and mismatch repair. In the present study, we found a correlation between the occurrence of lung cancer and gene polymorphisms of key genes in the BER, NER, and DSBR pathways (Qian et al., 2011). The authors of several studies have reported that three polymorphisms in DNA repair genes (rs13181 of ERCC2, rs861539 of XRCC1, and rs25487 of $X R C C 3$ ) affect the DNA damage repair process in cells (Kiyohara et al., 2012; Huang et al., 2013; Wang et al., 2013). In the present study, we found that rs 13181 of ERCC2 and rs 25487 of $X R C C 1$ are closely related to the risk of lung cancer, but there is no significant correlation between rs 861539 of $X R C C 3$ and the risk of lung cancer. This may be because the rs 861539 polymorphism of $X R C C 3$ is related to DNA adduct levels; the polymorphism may reduce the efficiency of DNA repair, but there is no obvious correlation with susceptibility to lung cancer. This inconsistent relationship requires further investigation.

Studies have shown that smokers with different genetic backgrounds have different levels of sensitivity to lung cancer. The early identification of a lung cancer-associated genotype would be of great significance to the prevention and active treatment of lung cancer. In the present study, statistical analysis was conducted on the correlation between rs4646903 and

Genetics and Molecular Research 15 (4): gmr15048813 
rs 1048943 polymorphisms of CYP1A1, rs1695 of GSTP1, rs13181 of ERCC2, and rs25487 of $X R C C 1$ and susceptibility to lung cancer. The results help explain the relationship between DNA damage repair and respiratory chain genes and susceptibility to lung cancer. They also provide a theoretical and practical basis for the analysis of clinical gene polymorphisms to predict the risk of lung cancer and improve early lung cancer treatment.

\section{Conflicts of interest}

The authors declare no conflict of interest.

\section{ACKNOWLEDGMENTS}

Research supported by Planning of Science and Technology in Guangdong Province (\#2016A020215162) and Planning of Science and Technology in Guangzhou City (\#2104YZ-00062).

\section{REFERENCES}

Abbas M, Srivastava K, Imran M and Banerjee M (2014). Association of CYP1A1 gene variants rs4646903 (T>C) and rs1048943 (A>G) with cervical cancer in a North Indian population. Eur. J. Obstet. Gynecol. Reprod. Biol. 176: 6874. http://dx.doi.org/10.1016/j.ejogrb.2014.02.036

Abdull Razis AF, Konsue N and Ioannides C (2015). Inhibitory effect of phenethyl isothiocyanate against benzo[a] pyreneinduced rise in CYP1A1 mRNA and apoprotein levels as its chemopreventive properties. Asian Pac. J. Cancer Prev. 16: 2679-2683. http://dx.doi.org/10.7314/APJCP.2015.16.7.2679

Brosh Jr RM (2013). DNA helicases involved in DNA repair and their roles in cancer. Nat. Rev. Cancer 13: 542-558. http://dx.doi.org/10.1038/nrc3560

Chen B, Zhou Y, Yang P and Wu XT (2012). Polymorphisms of XRCC1 and gastric cancer susceptibility: a meta-analysis. Mol. Biol. Rep. 39: 1305-1313. http://dx.doi.org/10.1007/s11033-011-0863-6

Choi JR, Park SY, Noh OK, Koh YW, et al. (2016). Gene mutation discovery research of non-smoking lung cancer patients due to indoor radon exposure. Ann. Occup. Environ. Med. 28: 13. http://dx.doi.org/10.1186/s40557-016-0095-2

García-González MA, Quintero E, Bujanda L, Nicolás D, et al. (2012). Relevance of GSTM1, GSTT1, and GSTP1 gene polymorphisms to gastric cancer susceptibility and phenotype. Mutagenesis $27: 771-777$. http://dx.doi.org/10.1093/ mutage/ges049

Ghoshal U, Tripathi S, Kumar S, Mittal B, et al. (2014). Genetic polymorphism of cytochrome P450 (CYP) 1A1, CYP1A2, and CYP2E1 genes modulate susceptibility to gastric cancer in patients with Helicobacter pylori infection. Gastric Cancer 17: 226-234. http://dx.doi.org/10.1007/s10120-013-0269-3

Hecht SS, Carmella SG, Chen M, Dor Koch JF, et al. (1999). Quantitation of urinary metabolites of a tobacco-specific lung carcinogen after smoking cessation. Cancer Res. 59: 590-596.

Hecht SS, Carmella SG, Murphy SE, Stepanov I, et al. (2016). Tobacco smoke toxicant and carcinogen biomarkers and lung cancer susceptibility in smokers. J. Thorac. Oncol. 11: S7-S8. http://dx.doi.org/10.1016/j.jtho.2015.12.011

Hezova R, Bienertova-Vasku J, Sachlova M, Brezkova V, et al. (2012). Common polymorphisms in GSTM1, GSTT1, GSTP1, GSTA1 and susceptibility to colorectal cancer in the Central European population. Eur. J. Med. Res. 17: 17. http://dx.doi.org/10.1186/2047-783X-17-17

Huang G, Cai S, Wang W, Zhang Q, et al. (2013). Association between XRCC1 and XRCC3 polymorphisms with lung cancer risk: a meta-analysis from case-control studies. PLoS One 8: e68457. http://dx.doi.org/10.1371/journal. pone. 0068457

Ibarrola-Villava M, Martin-Gonzalez M, Lazaro P, Pizarro A, et al. (2012). Role of glutathione S-transferases in melanoma susceptibility: association with GSTP1 rs1695 polymorphism. Br. J. Dermatol. 166: 1176-1183. http:// dx.doi.org/10.1111/j.1365-2133.2012.10831.x

Kiyohara C, Horiuchi T, Takayama K and Nakanishi Y (2012). Genetic polymorphisms involved in carcinogen metabolism and DNA repair and lung cancer risk in a Japanese population. J. Thorac. Oncol. 7: 954-962. http:// dx.doi.org/10.1097/JTO.0b013e31824de30f

Li D, Dandara C and Parker MI (2010). The 341C/T polymorphism in the GSTP1 gene is associated with increased risk of

Genetics and Molecular Research 15 (4): gmr15048813 
oesophageal cancer. BMC Genet. 11: 47. http://dx.doi.org/10.1186/1471-2156-11-47

Li W, Li K, Zhao L and Zou H (2014). DNA repair pathway genes and lung cancer susceptibility: a meta-analysis. Gene 538: 361-365. http://dx.doi.org/10.1016/j.gene.2013.12.028

Liu XL, Liu LD, Zhang SG, Dai SD, et al. (2015). Correlation between expression and significance of d-catenin, CD31, and VEGF of non-small cell lung cancer. Genet. Mol. Res. 14: 13496-13503. http://dx.doi.org/10.4238/2015. October.28.10

Malvezzi M, Bosetti C, Rosso T, Bertuccio P, et al. (2013). Lung cancer mortality in European men: trends and predictions. Lung Cancer 80: 138-145. http://dx.doi.org/10.1016/j.lungcan.2013.01.020

Malvezzi M, Bertuccio P, Rosso T, Rota M, et al. (2015). European cancer mortality predictions for the year 2015: does lung cancer have the highest death rate in EU women? Ann. Oncol. 26: 779-786. http://dx.doi.org/10.1093/annonc/ $\underline{\mathrm{mdv} 001}$

Mota P, Silva HC, Soares MJ, Pego A, et al. (2015). Genetic polymorphisms of phase I and phase II metabolic enzymes as modulators of lung cancer susceptibility. J. Cancer Res. Clin. Oncol. 141: 851-860. http://dx.doi.org/10.1007/ s00432-014-1868-Z

Qian B, Zhang H, Zhang L, Zhou X, et al. (2011). Association of genetic polymorphisms in DNA repair pathway genes with non-small cell lung cancer risk. Lung Cancer 73: 138-146. http://dx.doi.org/10.1016/j.lungcan.2010.11.018

Wang M, Chu H, Zhang Z and Wei Q (2013). Molecular epidemiology of DNA repair gene polymorphisms and head and neck cancer. J. Biomed. Res. 27: 179-192. http://dx.doi.org/10.7555/JBR.27.20130034

Xu CH, Wang Q, Qian Q, Zhan P, et al. (2013). CYP1A1 exon7 polymorphism is associated with lung cancer risk among the female population and among smokers: a meta-analysis. Tumour Biol. 34: 3901-3911. http://dx.doi.org/10.1007/ $\underline{\mathrm{s} 13277-013-0978-6}$

Zhao Y, Wang B, Hu K, Wang J, et al. (2015). Glutathione S-transferase q1 polymorphism contributes to lung cancer susceptibility: A meta-analysis of 26 case-control studies. Oncol. Lett. 9: 1947-1953.

Genetics and Molecular Research 15 (4): gmr15048813 